San Jose State University

SJSU ScholarWorks

Master's Theses

Master's Theses and Graduate Research

1993

\title{
The Perceived effects of nursing case management on patients following acute hospitalization
}

Nancy J. Woodward

San Jose State University

Follow this and additional works at: https://scholarworks.sjsu.edu/etd_theses

\section{Recommended Citation}

Woodward, Nancy J., "The Perceived effects of nursing case management on patients following acute hospitalization" (1993). Master's Theses. 604.

DOI: https://doi.org/10.31979/etd.pdz2-wbxf

https://scholarworks.sjsu.edu/etd_theses/604

This Thesis is brought to you for free and open access by the Master's Theses and Graduate Research at SJSU ScholarWorks. It has been accepted for inclusion in Master's Theses by an authorized administrator of SJSU ScholarWorks. For more information, please contact scholarworks@sjsu.edu. 


\section{INEORMATION TO USERS}

This manuscript has been reproduced from the microfilm master. UMI films the text directly from the original or copy submitted. Thus, some thesis and dissertation copies are in typewriter face, while others may be from any type of computer printer.

The quality of this reproduction is dependent upon the quality of the copy submitted. Broken or indistinct print, colored or poor quality illustrations and photographs, print bleedthrough, substandard margins, and improper alignment can adversely affect reproduction.

In the unlikely event that the author did not send UMI a complete manuscript and there are missing pages, these will be noted. Also, if unauthorized copyright material had to be removed, a note will indicate the deletion.

Oversize materials (e.g., maps, drawings, charts) are reproduced by sectioning the original, beginning at the upper left-hand corner and continuing from left to right in equal sections with small overlaps. Each original is also photographed in one exposure and is included in reduced form at the back of the book.

Photographs included in the original manuscript have been reproduced xerographically in this copy. Higher quality 6" x 9" black and white photographic prints are available for any photographs or illustrations appearing in this copy for an additional charge. Contact UMI directly to order.

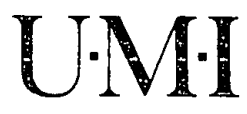

University Microfilms Internatıonal

A Bell \& Howell Information Company

300 North Zeeb Road. Ann Arbor. MI 48106-1346 USA

313:761-4700 800:521-0600 
$-$ 
Order Number 1953081

The perceived effects of nursing case management on patients following acute hospitalization

Woodward, Nancy J., M.S.

San Jose State University, 1993

Copyright (C1993 by Woodward, Nancy J. All rights reserved.

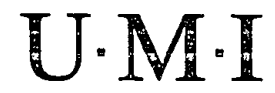

300 N. Zeeb Rd.

Ann Arbor, MI 48106 
THE PERCEIVED EFFECTS OF NURSING CASE MANAGEMENT ON PATIENTS

FOLLOWING ACUTE HOSPITALIZATION

\author{
A Thesis \\ Presented to \\ The Faculty of the Department of Nursing \\ San Jose State University \\ In Partial Fulfillment \\ of the Requirements for the Degree \\ Master of Science
}

By

Nancy J. Woodward

May, 1993 
APPROVED FOR THE DEPARTMENT OF NURSING

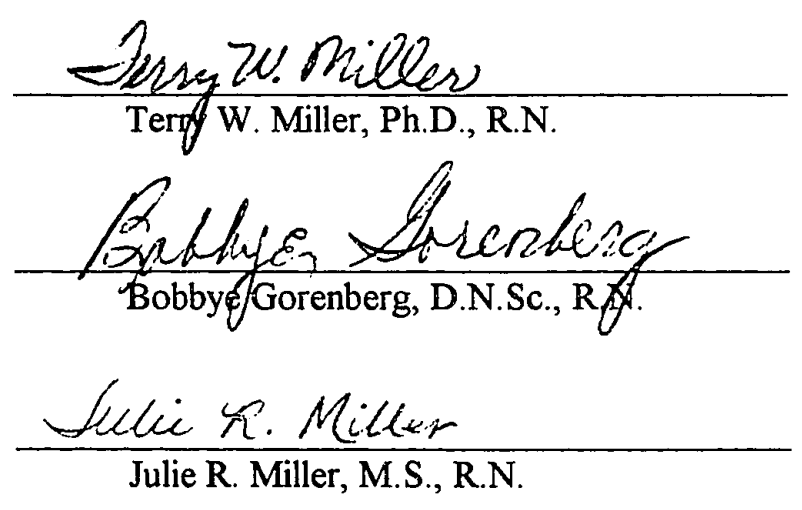

APPROVED FOR THE UNIVERSITY

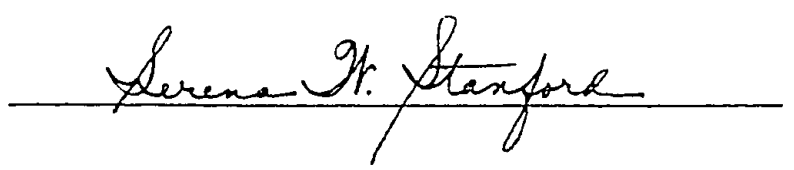




\title{
ABSTRACT \\ THE PERCEIVED EFFECTS OF NURSING CASE MANAGEMENT ON PATIENTS FOLLOWING ACUTE HOSPITALIZATION
}

\author{
By Nancy J. Woodward
}

Nursing case management is a method of care delivery developed to address the concerns of health care providers. These concerns are increasing costs, increasing demands, and decreasing resources within acute care hospitals. Many hospital areas have developed nursing case management programs. Few studies exist that examine the effect of these progranis from the patients' perspectives. This study sought to determine if there was a difference in the way patients perceived their needs were met in a case managed acute hospitalization compared to a non-case managed acute hospitalization.

Sixty-five patients receiving total joint replacements were treated in an acute care hospital, 42 case managed and 23 non-case managed. They returned mailed questionnaires containing 43 questions grading seven areas of care using a Likert-type scale of excellent to poor. Data were analyzed using crosstabulations and the Mann Whitney $U$. The results showed no significant difference between case managed and non-case managed in patient perceptions of care. 


\section{ACKNOWLEDGEMENTS}

The author would like to thank the faculty of the Department of Nursing at San Jose State University for their commitment to provide the knowledge and skills needed to conduct research and encouragement to do so.

Thanks to Judy Gallager for her assistance in the gathering of information for this study,

Mary Ann Haw for her help and encouragement,

My colleagues and staff at El Camino Hospital and

The Fund for Nursing Excellence for their funding and support,

Benjamin W. Woodward for his editorial

skills and his constant physical, emotional, and spiritual support; and, The Lord Jesus Christ. 


\section{TABLE OF CONTENTS}

Page

LIST OF FIGURES...................................................................... vii

\section{Chapter}

1. INTRODUCTION .......................................................... 1

Statement of the Problem ................................................... $\quad 3$

Purpose of this Study....................................................... 3

Research Question............................................................ 4

Definition of Terms ..................................................................

Summary .................................................................... 6

2. CONCEPTUAL FRAMEWORK AND REVIEW OF

LITERATURE............................................................ 7

Conceptual framework .................................................... 7

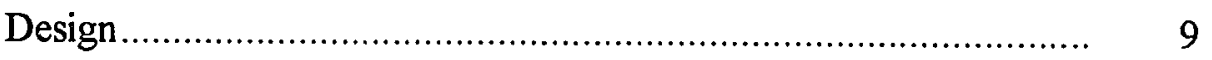

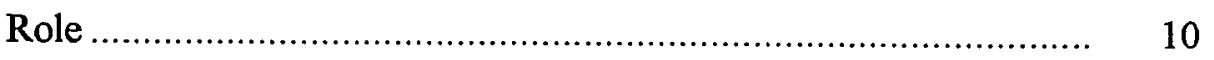

Feedback ................................................................... 10

Review of Literature ............................................................ 11

History of Nursing Case Management ..................................... 12

Outcome Measurements ................................................ 16

Patient Outcome Tools ........................................................ 18

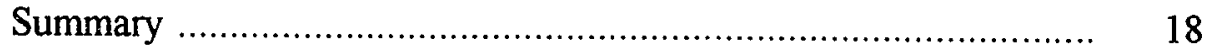

3. METHODS .................................................................. 20

Research Design ............................................................. 20

Subjects and Settings .................................................... 20 
Chapter

Page

Nursing Case Management Program ....................................... 22

Human Subjects............................................................ 23

Data Collection …................................................................. 23

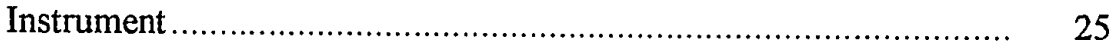

Analysis Procedures.................................................................. 27

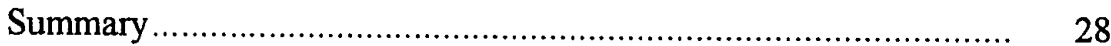

4. FINDINGS AND INTERPRETATIONS ............................... 30

Analysis of Data ....................................................................... 31

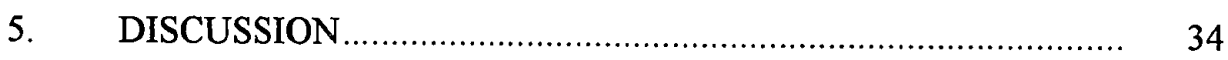

Scope and Limitations ............................................................. 35

Recommendations ....................................................... 37

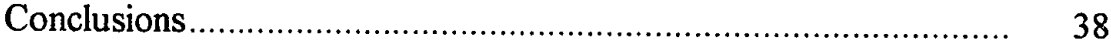

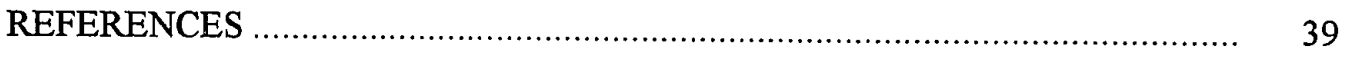

APPENDIXES

A. IRB Approval Letter .................................................... 43

B. Human Subjects-Institutional Review Board Approval Letter. 45

C. Questionnaire ................................................................. 47

D. Cover Letter .................................................................. 54

E. Patient Consent Form .......................................................... 56

F. Consent Letter to Use Questionnaire ................................ 58

G. Consent Letter to Reprint Conceptual Framework Diagram ... 60 


\section{LIST OF FIGURES}

Figure Page

1. Zander's Nursing Case Management Model .............................. 8 


\section{Chapter 1}

\section{INTRODUCTION}

Changes within health care reimbursement systems have led to development of new methods for nursing care delivery. The decrease in reimbursements resulting from Diagnostic Related Groupings (DRGs) place increased pressure on health care delivery organizations. Patients are being discharged from hospitals in a more fragile state of health than in years prior to the implementation of DRGs. Hospitals are limited in guaranteed income by a fixed amount of reimbursement per diagnosis. The pressure upon health care delivery systems is to manage care to achieve the most cost effective system and still maintain quality. The driving force of managed care is cost effectiveness leading to increasingly earlier discharges from acute care settings. Nursing case management is a method of organizing patient care directed at achieving the goals of cost containment, optimal patient health outcomes, and satisfaction both of the patient and the health care providers.

The elderly present a particular challenge to health care delivery systems. They consume a majority of health care resources and suffer from a proportionally high number of chronic illnesses. They also experience more acute exacerbations requiring hospitalization. Over $80 \%$ of the elderly contend with one or more chronic health conditions resulting in increased physician visits and more lengthy hospitalizations (Schefft \& Lehr, 1990). In addition, one out of five elders suffer some mild form of disability. Subsequently, elderly demands upon the health care system drive costs upward. The potential forces working against the cost containment of case management are patient outcomes in terms of early readmission rates, compromised safety, and decreased patient satisfaction. The atmosphere in which health care workers strive to provide services to meet the needs of an increasingly aging population is harsh and 
disheartening. Within this climaie of economic squeeze and increasingly complex patient needs, nurses should continue to monitor and evaluate the quality of care they deliver.

Total quality management (TQM) programs are the safety valve to insure the counteracting forces do not exceed the purpose of DRGs. TQM programs, in any business, function by assessing that the product specifications are met. TQM in health care includes the cost saving factors of the institution (the efficacious use of resources in delivery of care) and the end product of the business (patients, as determined by their health status and their perceptions of the hospitalization experience). Although institution-related effectiveness in goal achievement has been studied extensively, it has been from the perspective of the delivery system providers. A significant provider of the health care delivery system is nursing.

Nursing case management is the method of case management implemented in many acute care hospitals. Social service case management or insurance company instituted case management is currently being practiced through various health maintenance organizations (HMO). Social service case management provides referrals, social support and resource management but does not provide professional expertise in areas of health maintenance, especially for the ccmplex needs of elderly populations. Insurance company case management provides effective cost containment in many cases and is primarily performed by nurses, but it is subject to being overly focused on economic goals versus patient outcomes. Nurses traditionally serve as the primary patient advocates through their extended patient contact in an acute hospitalization and their knowledge of the physical, psychological, and social needs of patients. Nurses also function to administer hospital policies and meet the needs of the acute care institution.

The implementation of nursing case management in several hospitals has been studied and found to be effective in meeting DRGs, reducing patient readmissions, and maintaining health related quality of care (Zander, 1988). The outcome of patient 
satisfaction through the patients' perceptions of their care delivery, however, has not been adequately measured. Nursing has a responsibility to serve the care delivery institution but has a greater responsibility to serve the patients and to assess the quality outcomes of care delivery changes from the patients themselves (Vuori, 1987).

\section{Statement of the Problem}

DRGs continue to lead a prospective drive downwards in health care reimbursement. In turn, this downward drive causes a broader interest to be given to the benefits of managed care as a means of meeting DRG restrictions. It is believed that development of case management plans for specific DRGs throughout the country benefits health care providers through cost containment (Cohen, 1991).

Attempts to meet DRG requirements may significantly affect patients' perceptions of their hospital care. Whether or not there is a difference in patient perceptions of care after the implementation of nursing case management is a question that nurses need to address. Geriatric patients have unique needs during hospitalization that may be affected by nursing case management of their hospital stay. They have decreased muscle mass which contributes to difficulty maintaining physical therapy regimes. Their sensory perception is frequently altered or diminished. They have difficulty in following through with instructions that they are unable to read well or hear fully (Longino, Soldo, \& Manton, 1990). The unique needs of geriatric patients and their increasing share of the utilization of health care resources demand concentrated attention be given to their needs.

\section{Purpose of this Study}

This study focuses on the patient's perspective of quality of care by determining what patients' perceptions are of their acute care hospitalization. Patients' perceptions of care are examined through the case management process compared with patients' perceptions of non-case managed acute care hospitalizations. This researcher commends 
attempts to control skyrocketing costs but recognizes that patient outcomes must be part of the evaluation of the quality of health care delivery. Full evaluation of patient outcomes must include the perceptions of the patient, a missing factor in much of the implementation of case management. Assessment of the patient's perspective of care has yet to be completed in most established case management programs. This study addresses patient perceptions of their hospitalization experience. Six areas of the hospitalization experience are included. These areas are admission, hospital care, nursing care, physical living arrangements, physician care, and discharge procedures.

\section{Research Question}

This study sought to answer the following research question: Is there a difference in the way patients perceive that their needs are met in a case managed acute hospitalization compared to a non-case managed acute hospitalization? The researcher gathered information on patient satisfaction throughout an entire hospitalization encompassing six areas of care. To find the answer to this question a patient questionnaire was used. The questionnaire assessed patient perceptions of care through admission, hospital care, nursing care, physician care, living arrangements, and through the discharge process. The null hypothesis tested was that the satisfaction reported by case managed patients is no different than the satisfaction reported by non-case managed patients.

\section{Definition of Terms}

For the purpose of this study, the following definitions apply:

1. Case managed acute hospitalization is case managed care in an acute care facility. This does not include care in a convalescent hospital, rehabilitation, skilled nursing facility, or facility providing primarily custodial care.

2. Case management is a process of organizing patient care through one primary person, the Professional Case Manager, who oversees the hospitalization and facilitates 
timely and efficacious use of hospital resources.

3. Diagnostic related groupings (DRGs) are designated maximum reimbursements assigned by Medicare, Medi-Cal, or private insurance agencies for specific diagnoses treated in acute care hospitals. All patients included in this study were assigned the DRG classification number 209 which includes the diagnoses of total hip and total knee replacement.

4. Geriatric patient is a patient over 60 years of age who has been hospitalized in an acute care facility.

5. Length of stay (LOS) is the number of days a patient is in the acute care hospital. When LOS exceeds the number of days allowed by the DRG classification, the patient is classified as an "outlier." As a result, the remainder of the hospital stay is subject to denial of reimbursement by the third party payer (insurance, Medi-Cal, or Medicare).

6. Professional Nursing Case Manager (PNCM) is a Registered Nurse skilled in management. The PNCM is a clinical expert in a specific diagnosis area and accountable to management for meeting the outcomes of LOS, following established protocols, and bringing in needed resources. The PNCM oversees care for each patient from the admission of the patient to the acute care hospital until discharge to include arrangement for needed care following discharge.

7. Case Management Plan (CMP) is a written plan incorporating an entire hospitalization with timelines within which specific interventions are scheduled to occur. Often the CMP is referred to as a critical pathway and is unique to each DRG. The CMP guides caregivers by incorporating standing orders specifying actions to be taken when deviations from timelines occur. 


\section{Summary}

The health care delivery system throughout the United States has become exceedingly expensive. Changes in reimbursement are imminent as economic resources diminish and health care demands increase. The conflicting forces of limited reimbursements through DRGs, earlier discharge from the hospital, and the needs of an aging population place a tremendous strain on the health care system. The balance of these forces through nursing case management affords a highly patient focused solution. The raison d'etre of the health care industry is the patient. Foremost in any health care delivery TQM program must be the view from the bed. The quality question the researcher addresses is: Do patients perceive that their needs are being met through a case managed hospitalization compared to a non-case managed hospitalization? 


\section{Chapter 2}

\section{CONCEPTUAL FRAMEWORK AND REVIEW OF LITERATURE}

\section{Conceptual Framework}

The conceptual framework for this study was Zander's Nursing Case Management Model (1988). Zander developed and implemented her nursing case management system at New England Medical Center Hospitals in Boston. Zander (1988) claims to have achieved five goals:

1. early patient discharge or discharge within an appropriate length of stay;

2. 'expected' or 'standardized' clinical outcomes;

3. promotion of collaborative practice, coordinated care, and continuity of care;

4. use of appropriate or reduced resources; and

5. promotion of nurses' professional development and satisfaction (p. 28).

Zander's systems model represents a linking of structure, product, and process through a feedback system. She uses the roles of nurse and physician within the framework of the design (see Figure 1). All factors are centered on the patient and family. The model was developed over 13 years with a 2 year investigation of the outcomes of care.

This study provides information related to the feedback section of Zander's model. Zander's second and third goals are in effect quality outcomes, and inclusive of expected clinical outcomes and collaborative practice, coordinated care, and continuity of care. The patient questionnaire used in this study specifically addresses Zander's quality issues and provides feedback from patients as to whether their needs are being met. Therefore, this study relates directly to the three primary concepts in Zander's model. These concepts are design, role, and feedback. 


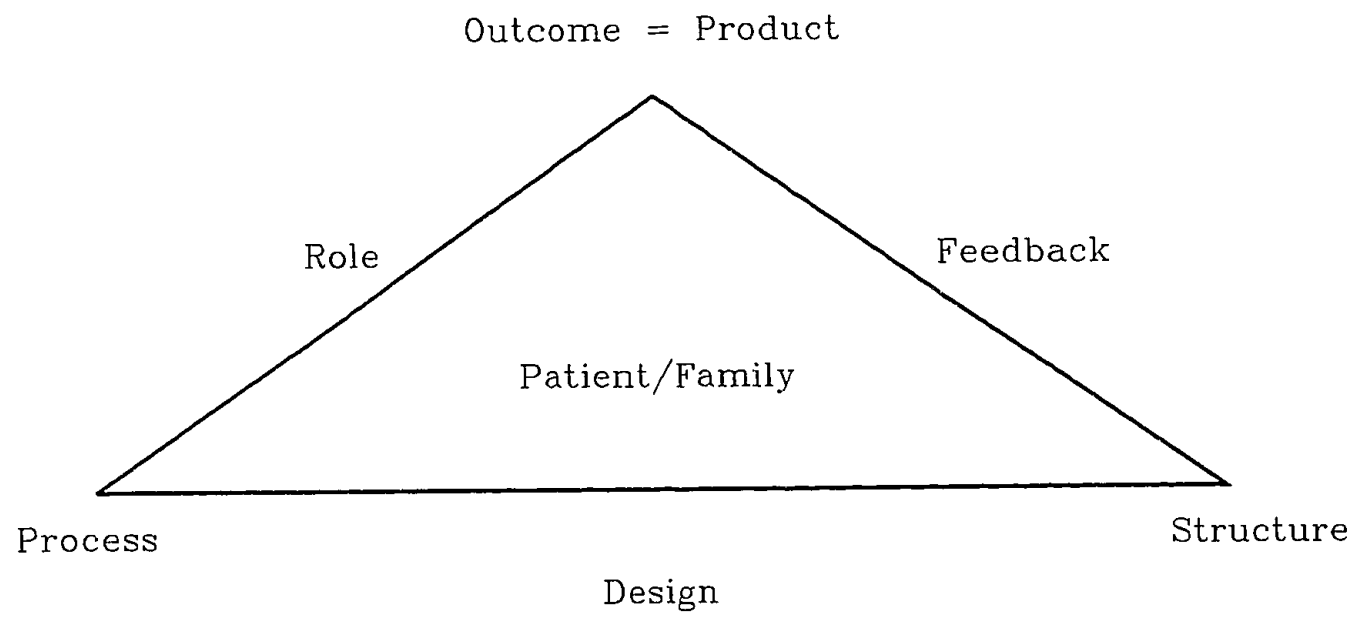

Figure 1. Nursing case management model.

Note. From "Managed care within acute care settings: Design and implementation via nursing case management" by K. Zander, 1988, Health Care Supervisor, $\underline{6}(2)$, p. 30. Reprinted by permission. 
Design

Design is described as the way the structural components, or case management plan (CMP), is conducted to support the outcome. Zander (1988) refers to the CMP as a second generation nursing care plan which uses timelines, specific time frames, and scheduled interventions to address a continuum of problems. The role of professional nurse case manager (PNCM) collaborator becomes paramount in developing the ongoing physician and clinical nurse specialist (CNS) design. Spross (1989) states that the CNS collaborator's, "clinical, interpersonal, and organizational skills may be able to shift the balance so that cost containment becomes a driving force" (p. 208). DRG-related cost containment is, of necessity, a part of the common purpose of CNS and physician collaboration. The complementary skills and efficacious communication of the CNS are essential for a comprehensive CMP.

Zander (1988) states that timelines provide a clear definition of episode-based care for health care providers, patient and family. A timeline encompasses the entire anticipated length of stay (LOS) and specifies when necessary lab work, physical therapy or treatment regimes should occur. Timelines provide a basis for accountability to the CNS and are incorporated in the CMP specific for each DRG. The critical path is used throughout the LOS, through different levels of care, with case variations and specific actions noted. The CMP becomes a teaching tool for new staff and guides early intervention of discharge planning and scheduling of diagnostic tests.

Zander's conceptual framework provided guidelines for this study in the use of timelines through CMPs. With the case managed group in the researcher's study, the CMP called for discharge planning to begin prior to admission to the hospital through the interventions of the PNCM. Patients were introduced to their critical path or plan of care which enabled them to anticipate and plan for the stages of their hospitalization. They were informed that certain tests would be performed at scheduled intervals. They were 
introduced to the physical therapy that would be an integral part of their recovery and through the PNCM were empowered in their care through knowledge and accountability.

\section{$\underline{\text { Role }}$}

The actual application of the design using a critical path is done through those who direct patient care, the physician in conjunction with the PNCM. The case manager is skilled in management, a clinical expert within the critical pathway, accountable for meeting the outcomes of LOS, following established protocols, and bringing in needed resources. Zander (1988) provides a CMP checklist to guide the CNS. The CNS's authority should extend over all units within which the patient is placed. The advanced practice skills required for case managers is best met by a master's prepared CNS with expertise in the assigned critical pathway or DRG.

The nature of health care requires flexibility at every level. The PNCM must be able to respond to unanticipated setbacks due to breakdown in care delivery or delayed patient recovery. These setbacks are called variances in the CMP and are addressed through the ongoing evaluation of the PNCM. In this way, trends are revealed that can signal needed changes in care delivery or planning.

\section{Feedback}

The effectiveness of nursing case management should be evaluated through an ongoing process. At the New England Medical Center Hospital each case is reviewed in relation to actual costs of interventions and outcomes, giving the clinician a broader understanding of cost and quality. A four part audit consisting of two foci is conducted on each primary nurse case manager. The two foci are the process of care provision, and outcomes of care, both form a basis of meaningful research in nursing case management. Holt (1990) states in relation to the importance of the CNS, "The bottom line is that we need to continue to study the variables contributing to positive patient care outcomes including careful evaluation of the impact and cost of the variety of health care providers" 
(p. 141). This study provides feedback information on quality of care within Zander's framework. Outcomes of care as determined by the patients' perceptions provide a subjective and valuable means of feedback to evaluate the care delivery system in use.

Evaluation is an ongoing process as each hospital shift over a 24 hour period addresses the goals of the CMP and the primary nurse assumes responsibility for meeting or addressing any variances. Evaluation also needs to include care after discharge or follow-up care. This may be accomplished through telephone follow-up or may necessitate a home visit. One area of revenue loss for hospitals is readmission within a short period of discharge for which insurance reimbursement is often denied. Evaluation that identifies the need for intervention or home follow-up can save the institution money in the long run. Cronin and Maklebust (1989) emphasize the role of the CNS in evaluating care needs preventing premature discharge when necessary. The CNS is also in constant collaboration with the Utilization Review Department to utilize less expensive modes of care for day outliers (those whose LOS exceeds the number allotted for in their specific DRG).

\section{Review of Literature}

The review of literature covers the development of nursing case management and the development of measurement tools. Nursing case management in its present form has been evolving over the past 20 years. The applications of the concepts of nursing case management have taken increasingly more varied expressions. The literature review provides information on nursing case management implementation within several settings. At the current time, the field of nursing case management and its application are exploding logarithmically. Case management programs are being developed for psychiatric inpatient and outpatient clinics, home care, and acute medical care. Outcome measurement is an area gaining increasing interest in the current economic climate of greater cost containment. The daily press present scenarios of the woeful state and 
future of the health care system's economic base. Meanwhile, capturing a cogent and thorough picture of the effectiveness of the current patterns of delivery challenges those who seek to improve it. Changes in health care delivery affect people. Providers of care, such as nurses along with all other members of the care delivery team, are affected. Those most directly affected are the patients who often come into a health care system vulnerable and hurting, and whose perceptions should be carefully considered in evaluating measurement outcomes.

\section{History of Nursing Case Management}

Wahlstedt and Blaser (1986) developed the Nursing Assessment and Management of the Frail Elderly (NAMFE) study through a federal grant in response to increased demands by reimbursement reductions. The high incidence of comorbidity in geriatric patients combined with an aging population have brought a challenge to health care delivery. Out-of-hospital care is expanding with an increased need for management of the continuum of care. The NAMFE study sought to meet the health care needs of frail elders through the use of community health nurse case managers. The program succeeded in maintaining elders in their own homes with PNCM support. The researchers determined that although community health nurses are skilled in coordinating care and resources they may require additional education in role preparation to meet the challenge of case management.

Cronin and Maklebust (1989) describe Detroit's Harper Hospital CNS case manager program. The program was based on Zander's (1988) model and used 30 master's prepared CNS case managers with a case load of 20 patients each, matching diagnoses to the clinical speciality of the CNS. Clinical savings were realized through the use of early interventions, early discharge planning, referrals to community resources, and timely discharges with reductions in unnecessary readmissions. Comprehensive documentation by the CNS also served to reduce the number of non-reimbursable 
hospital days, further increasing revenue. This study failed to record any direct evaluation from patient perspectives.

Dunston (1990) has applied Zander's (1988) model for use at Rose Medical Center in Denver, Colorado, with 21 critical pathways for specific diagnoses currently in use and 25 additional plans being developed. Dunston sees one of the biggest advantages of case management as being the added involvement of patients in planning their care and tracking their case progress. However, Dunston failed to mention how the subjects of the study were followed to obtain perceptions of how patients viewed their hospitalization and felt they were able to manage their care.

Ethridge and Lamb (1989) of Carondelet St. Mary's Hospital and Health Center in Tucson, Arizona, have conducted research showing reductions in LOS and cost through nurse case managed care in the acute setting. Using a team nursing approach, the PNCM is, "responsible for assessment of patient and family, establishment of the nursing diagnoses, developing the nursing care plan, delegation of nursing care to associates, activation of interventions, coordination and collaboration with the interdisciplinary team and evaluation of outcomes" (p. 30). The researchers believe quality of care is directly related to professional accountability, continuity of care, and PNCM educational preparedness. Throughout the study, the average LOS declined from 10.2 days to 8.1 days. A retrospective study of case managed versus non-case managed cases over 3 years shows a dramatic decrease in LOS, patient acuity, and nursing staff time required. From a cost effectiveness viewpoint, the case management program was a success which encourages expanding case management to other areas. It is unlikely that any program which increases overall costs will survive in the economic climate of the '90s. The retrospective study fails to measure quality outcomes from a patient viewpoint.

Williams (1991) has found that the relationship of nursing case management models to nursing conceptual models lacks specification and clear usefulness. Williams 
believes this lack is due to the development of nursing case management which came from nursing practice administrators who based their design on management theory and concepts rather than nursing theories. Williams has found, as well as this researcher, that the model most frequently cited in nursing case management articles is the New England Medical Center Model. Williams states the nursing administration practice has not maintained theoretical growth as have other nursing specialities. Williams believes the reliance of nursing administration on management theories has placed the entire nursing discipline at risk through loss of nursing focus. Williams emphasizes this risk and contends that nursing frameworks developed outside of collaboration with nursing practice do a disservice in reinforcing nursing theoretical uselessness. Williams further recommends that more emphasis be placed upon outcome measurements and their connection to reality based practice problems.

Lulavage (1991) describes the implementation of nursing case management using RN-LPN teams following the New England Medical Center model. Having limited resources, most particularly few advanced practice nurses, the researchers proceeded to design a program eliminating some of the management staff and using staff nurses to fulfill the roles needed. The researchers reported raised morale within the staff and reported good communication with medical staff. They have not, however, evaluated the quality of the progian from the patient perspective and have not expanded the program into other areas of the hospital. Using team managed care instead of PNCMs may suit more institutions and unit based programs which have limited resources to start up a program. One of the drawbacks to setting up such a program is the obvious difficulty middle management might have to the potential loss of positions. This might, however, fit well into an overall hospital cost-containment program that is seeking to create a flatter structure.

Pittman (1991) has described a case management model for acute hospitalizations 
she calls CARE. The components of the model are C--Case managed/coordinated care, A--Atraumatic principles, R--results through interactive planning, and E--empowerment. In the empowerment aspect of the model, Pittman stresses the accountability of nursing to expand their emphasis on patient outcomes as a logical step in a patient-centered, customer-driven model. Pittman notes that nurses who subscribe to this model will be required to expand their present knowledge base beyond the current requirements of the hospital nurse. In order to act more effectively for the patient, nurses will be required to expand their understanding of resources and budgeting. While the rewards of increased professionalism will be attractive to many nurses, the resistance to change within the ranks of nursing can present a formidable blockade.

Norris and Hill (1991) address the role of the CNS in the role of case manager. They state the components of the role that have the most impact on patient outcomes are patient selection, health assessments, planning and coordination of care, and monitoring and evaluation of outcomes. They encourage PNCMs to share the critical path with the patient and family at admission to increase understanding of their course of care. Norris and Hill report that the most important members to include in an evaluation of effectiveness are the patient and family; however, they do not recommend any particular method to accomplish this process.

Many nursing case management programs have produced significant savings but not all have been successful. Henderson and Collard (1988) report on a medical case management program focusing on severe illnesses or injuries requiring intensive care. Of the patients referred, only $20 \%$ were chosen for case management due to the expected high costs of their care. While the researchers acknowledge that case management did not save money in every case, there was an appreciable increase in the quality of care overall and more options for patients and providers for alternative treatiments.

Wimberley and Blazyk (1989) studied a computerized geriatric case management 
system and found that greater access to patient data was achieved improving discharge planning capabilities. They discovered drawbacks, however, in increasing staff tension as the changeover to computer use progressed. Administration prioritized the report and information processing aspects of the program while services staff emphasized the service oriented features and tended to ignore the data requirements. It was realized that resistance to computer use in case management should be addressed early on with attention given to staff training and cooperation in the formative stages.

Henderson, Souder, and Bergman (1987) evaluated a first generation case management program focusing on short term savings realized within 6 months of the implementation of case management. Of 120 cases, only $29(24 \%)$ were found to have short term cost savings outweighing the cost of the case management service. The 29 cases saved approximately $\$ 430,000$. The cost of case management was $\$ 191,000$, yielding a cost to benefit ratio of $\$ 1: \$ 2.25$. When the 92 cases without short term savings were analyzed, the cost of case management was $\$ 684,000$ for all 120 cases. For every $\$ 1$ spent $\$ 0.63$ was saved. High risk infants were the only group that showed savings across the board. The authors admit that looking at long term savings could change their figures dramatically. The researchers emphasize that case management was in the early developmental stage throughout their data gathering period.

\section{Outcome Measurements}

Geigle and Jones (1990) studied the strengths and weaknesses of outcome measurements and addressed the role of the patient in determining outcomes. Most providers concur that the ideal measurement of quality is the patient's quality of life. The patient has largely remained on the periphery of actual measurement but patient involvement is increasingly being sought on a formal and informal basis to evaluate the outcomes of an episode of care. Patient values and risk preferences must be taken into consideration in deciding which treatments are best. Geigle and Jones (1990) consider 
the patient, "the most reliable guide in a world of incomplete data and largely incomplete measurement tools" (p. 12). They recommend that hospitals, "Structure themselves and commit resources to assure quality, hire individuals and establish systems that will guarantee quality....Develop protocols for how selected diagnoses and conditions will be treated, then measure the results of the protocols on those conditions" (p. 11). Geigle and Jones (1990) have presented a case management plan for nursing. Although it may be undeliberate, it reads like a prescription for nursing case management and the quality outcome evaluation this study presents. Following the guidelines in Geigle and Jones, this study uses a questionnaire to elicit responses from patients of their perceptions of the care they received.

Vuori (1987) states, "It is the patient who literally feels it in the skin if something goes qualitatively awry in health care. Yet systematic measurement of patient satisfaction is seldom included in routine quality assurance programs" (p. 106). Vuori reminds us that quality is a culturally dependent concept, but caregivers have an ethical imperative to involve patients in TQM. Although Vuori does not address case management per se, the focus given to having the patient's needs and wishes taken into account as an essential consideration of well-being clearly fits into the case management model and this study.

Ethridge (1991) corroborates Vuori's views in the Carondelet St. Mary's case management program. She states:

Our clients consistently tell us that the nurse case managers have helped them recognize and manage early warning signs of acute exacerbation of their chronic illness. This, they feel, enables them to remain at home and out of the hospital. Our clients also tell us they feel more confident and competent in caring for themselves (p. 25).

Unfortunately, Ethridge failed to quantify the reported patient satisfaction. Vuori (1987) believes it is possible to measure patient satisfaction in a valid and reliable way. This 
study sought to provide information in that area.

\section{Patient outcome tools}

Winslow (1992) reports on the results of a patient questionnaire on quality of life following hip replacement surgery at New England Medical Center. The results have revealed patients take longer to heal to full functional ability than patients had been led to believe they would. These data have led physicians to change the information they teach patients so that patient expectations are more realistic.

Rubin (1990) has written a comprehensive review of 102 patient evaluation tools including information on their strengths, weaknesses, area of focus, validation, and reliability. The tools reviewed include information on all areas of care, including nursing, medical, special therapy, housekeeping, dietary and billing services. Rubin's research has found that using a Likert-type, 5-point, excellent to poor scale is most effective in obtaining reliable patient evaluations.

Meterko and Rubin (1990) developed a taxonomy of patient judgements of hospital quality to guide the researcher. They used two sources of patient data to develop guidelines for questionnaire development, verbatim written comments, and focused group discussions. Review and analysis of patient data resulted in a taxonomy of patient concerns. Meterko and Rubin's (1990) research was a basis for the development of the patient questionnaire used in the present study.

\section{Summary}

The literature reveals nursing case management is a method of care delivery gaining wide acceptance in an effort to reduce costs and manage resources. Zander's jonceptual framework (1988) stresses that feedback be an integral part of the nursing case management model. Zander places the patient in the center of her model. The outcome, or product, is the end result of the care delivery system. This outcome is a combination of physical, psychological, and emotional well-being that is measurable. The 
case management programs reviewed by this researcher have focused primarily on the measurable physical outcomes of the patients. The feedback process involving expected or standardized patient outcomes also requires subjective input. Evaluation of care delivery needs to be ongoing as Zander's model directs. The design, or CMP, is a flexible tool that must be evaluated in relation to the feedback received. The feedback then directs the PNCM to make needed changes in the role deciding how the CMP is carried out or needs to be changed. This researcher is guided by Zander's model to select an appropriate measurement tool and elicit subjective feedback from the primary recipient, the patient, to determine the quality of care which is the ultimate product.

This researcher is aware that any program related to the movement to drive health care costs downward has the potential to affect quality which can be evaluated best from a direct patient assessment. TQM programs cannot be conducted with validity if they lack consideration of the patient's perceptions (Vuori, 1987). In the nursing case management programs reviewed, none contained a thorough evaluation of care from the patient perspective. A focus on patient perceptions of care has been lacking in many quality assurance studies of health care delivery systems. This study sought to fill that void by first establishing the baseline of patient perceptions of care with a non-case managed group. This evaluation was followed by the intervention of case management with a similar group of patients whose perceptions were then evaluated using the same tool. The comparison of these two groups provides hospital personnel a greater understanding of the patients' point of view of both the old and the new delivery systems. With a better understanding of patient perceptions, new programs and existing programs can be enhanced to better meet patient's expressed wishes. As nursing case management programs are implemented within hospitals, obtaining a baseline of current patient attitudes about their care prior to case management and after implementation will allow for comparison evaluations of the care delivery systems. 


\section{Chapter 3}

\section{METHODS}

\section{Research Design}

The design of this study was a quasi-experimental design using a mailed survey questionnaire. The questionnaire was used to evaluate perceptions held by patients of their hospitalization experience. Two groups were studied and their responses to an identical questionnaire were statistically compared to evaluate patient perceptions of a nursing case management program versus a traditional care delivery system. The two groups consisted of a non-case managed group and a case managed group. The first surveys were mailed to non-case managed patients within 8 weeks following discharge from the hospital. These surveys provided the basis for an analysis of patient perceptions of their experience prior to hospital implementation of nursing case management. Permission to use these data and analyze them was received from the department head of the study unit.

Three to 6 months after implemeritation of nursing case management, surveys were mailed to a second group of patients. The results of the non-case managed patient surveys were compared to the results of the surveys from case managed patients and analyzed for statistical significance. The results of the study were part of a hospital-wide case management program evaluation conducted in a district hospital in northern California.

\section{Subjects and Settings}

The subjects for the study were selected from patients hospitalized for total joint replacements of either a hip or knee. All were assigned the DRG classification of 209. The patient group was selected for convenience, because the participating hospital had initiated a program of nursing case management with total joint replacements. The total 
joint replacement patients were primarily geriatric, Caucasian, and female. Women receive more total joint replacements than men and represent a significantly greater proportion of the geriatric population (Longino, Soldo, \& Manton, 1990). It should be noted that this population is unique from other hospitalized patients as they planned their hospitalization in advance with their physicians to address a chronic problem as opposed to an acute episode. They may not be representative of other types of patients with other diagnoses.

The sample selected included 99 patients. All of the total joint replacement patients admitted to the orthopedic unit during the data gathering periods of time were eligible to participate. The non-case managed group contained 40 , the case managed group contained 59. Each patient in the case managed group was personally asked for permission to have the questionnaire mailed to her or him. Two refused to participate. Fifty-seven questionnaires were mailed out with a return of 41 . Reminder letters and questionnaires were mailed out to non-respondents with an additional return of 2 questionnaires. Twenty-three questionnaires were returned from the non-case managed group. No prior permission was obtained from the non-case managed group as this was part of a hospital evaluation program.

The setting for the study is a 350 bed community district hospital in a predominantly middle class suburban area. The unit selected for conducting the research was the orthopedic unit of the hospital, a 34 bed medical and surgical unit specializing in caring for orthopedic patients. The department head of the unit recently introduced a new care delivery system to the unit, nursing case management, to be implemented on all total joint replacement patients. This change provided an opportunity to evaluate the new care delivery system and compare it to the traditional method of care delivery. The department head had completed gathering data of patient perceptions of their hospitalization experience prior to initiation of the new case management program. 


\section{Nursing Case Management Program}

The nursing case management program was conducted by the PNCM. The PNCM contacted the department of surgery weekly and obtained a list of the total knee and total hip replacements that were prescheduled for surgery. Each patient was contacted by telephone 2 to 3 weeks prior to the scheduled surgery date and invited to a class 7 to 10 days prior to their scheduled surgery. During this class, held each Tuesday, the patients were preadmitted to the hospital and given financial counselling. Each class consisted of 3 to 5 patients. The class met for 30 minutes as a group during which they were introduced to the critical pathway or expected progression of care they would experience. The patients were given written information during this first 30 minutes that further explained the hospital procedures that would be part of their plan of care. Equipment that would be implemented in their care was also introduced to them during this group time. After the 30 minute group time, the class was divided into two separate groups. They then spent 20 minutes with a physical therapist who instructed them in the type of therapy they would be participating in following surgery. At the same time, the other group was spending 20 minutes with an occupational therapist learning the various types of therapy they would be participating in following surgery.

After the class the PNCM then met with individual patients as they finished with the therapists and did a brief physical assessment and recorded a patient history. This history included a heaith systems review, social history, plans for discharge, assessment of home environment, determination of primary care giver following discharge, and review of previous health history. Following the assessment, the PNCM gave each patient a tour of the unit. Each patient was contacted by telephone within 2 days following the Tuesday class, and additional information was gathered by the PNCM. The surgeons had participated in the original planning of nursing case management and had contributed to development of the critical pathways. The PNCM acted in each part of 
the case management process with the full knowledge and support of the surgeons.

Human Subjects

A proposal to conduct the study was presented to the hospital Institutional Review Board (IRB). The IRB stated, "the study would gain more significance if a randomized design had been employed." Approval was given to conduct the research as stated in the protocol (see Appendix A). Approval also was received from the San Jose State University Human Subjects-Institutional Review Board to conduct the research (see Appendix B).

\section{Data Collection}

All questionnaires were mailed to total joint replacement patients within 2 months of discharge from an acute care hospital. The questionnaire was first mailed to patients who had not received case management during acute hospitalization. Several months later, after implementation of case management, an identical questionnaire was mailed to case managed patients with the same diagnoses, hospitalized in the same unit of the hospital.

The non-case managed group of patients was admitted the evening prior to surgery for joint replacement. They were treated by their physicians and nurses, and discharged according to the physician's orders. The secretary of the nursing unit to which the non-case managed group was admitted mailed these patients a questionnaire (see Appendix C) and cover letter (see Appendix D) requesting anonymous opinions of the care received throughout admission, hospitalization, and discharge. A self-addressed, stamped envelope was enclosed with each questionnaire for the patient's convenience. The first mailing was initiated by the department head who, according to hospital policy, was not required to gather prior consent from the subjects.

The questionnaire was mailed to the group of non-case managed patients within 8 weeks of discharge from the hospital. If no questionnaire was returned within 3 to 4 
weeks, a reminder letter was mailed with another questionnaire. The department head oversaw the mailings to the non-case managed group and assigned the job of record keeping to the department secretary. Forty questionnaires were mailed out, and 23 questionnaires were received back from the non-case managed group of patients. A number code was kept by the department secretary to track the patients who had received and returned the questionnaires to facilitate remailing.

Approximately 6 months following the implementation of nursing case management, a group of case managed patients was selected to evaluate their care using the same questionnaire. The information gathered from the case managed patients required prior approval of the hospital's Institutional Review Board, approval of the University supporting and overseeing the research, and an approved consent form from each patient granting permission for the questionnaire to be mailed to them (see Appendix E).

The researcher screened the study unit patient population a minimum of twice weekly to identify patients meeting the study requirements. As total joint replacement surgery patients were identified, they were listed on a patient log kept by the researcher and assigned a number. After the second day of hospitalization these patients, if available, were approached by the researcher. The patients were given an explanation of the research being conducted and asked for permission to be included through the mailing of a questionnaire. They were told that the research was to assess the quality of the care they received and that their honest responses were requested so that areas needing attention could be identified. They were told which patients were being included and the number of participants desired by the researcher. If they agreed to participate, they were asked to read and sign a consent form and were given a copy of it with instructions to call the researcher with any further questions they might have. Each patient was thanked for their time and assured of their anonymity regardless of their agreement or refusal to 
participate. The non-case managed patients did not sign a consent form prior to mailing a questionnaire to them. The data from the non-case managed group were gathered by the department head in accordance with hospital procedures and was existing data available to this researcher.

After consent was given by a patient to be mailed the questionnaire, demographic data were obtained. Each participating patient was accessed in the computer to obtain a mailing address. This was done in accordance with the protocol approved by the hospital's Institutional Review Board and the unit department head.

The researcher maintained a log of all patients who were approached to participate in the study during the data gathering time, approximately 4 months. Each patient was assigned a number which corresponded to the number on the consent form and the number on the questionnaire. As the questionnaires were received in the mail, patient names with the corresponding numbers were checked off on the log. Questionnaire numbers which were not received by return mail were noted. These patients were remailed another questionnaire and cover letter 1 month after the original mailing. Fifty-seven questionnaires and 12 follow-up questionnaires were mailed out.

Copying of questionnaires, consent forms, and cover letters was done at hospital expense. Time required for checking unit records and participating patient records, patient contact, and communication varied from 2 to 10 hours per week. Questionnaires were mailed with a postage-free, return-addressed envelope attached to the questionnaire directing it to be sent to the study unit of the hospital. The secretary on the study unit collected the returned questionnaires, clearly marked for the researcher for pick up by the researcher.

\section{Instrument}

The questionnaire was developed using Meterko and Rubin's guidelines (1990) which were adapted by Haw (1991) as part of the evaluation program of the hospital 
nursing case management program. Permission was granted by Dr. Haw to use the questionnaire in this study (see Appendix F). The questionnaire contains 7 sections plus demographic information totaling 54 questions. All the questions except the demographic questions and the comment areas may be answered using a 5-point, excellent to poor scale which has been found to be the most reliable way to ask questions on patient questionnaires (Rubin, 1990). Using such a scale also allows for convenient statistical analysis. For the purpose of this study, only the first 43 questions were analyzed statistically. These 43 questions were answered by using a 5-point scale rating care as excellent to poor.

The first section of the questionnaire addresses admission procedures or entering the hospital. It contains 4 questions. These questions relate to areas regarding preparation for admission, efficiency of the admission procedure, helpfulness and concern of the admitting staff, and attention of staff to individual needs.

The second section addresses care in the hospital. It contains questions in 14 areas. These areas are: medical facilities, overall efficiency, recognition of patient opinions, consideration of patient needs, information received, instructions received, coordination of care, daily routines of medical, nursing and hospital staff, informing family and friends, involving family or friends in patient care, ease of getting information, specialists and special therapy, helpfulness, and safety and security.

The third section focuses on nursing care and contains 5 questions. These questions ask for patient judgements of the skill and competence of the nurses. Patients are asked about attention given to the patient's condition, nursing staff responses to patient calls, concern and caring by nurses, and information given by nurses.

The fourth section asks for patient judgements of their doctor's performance in five areas. Patients are asked to evaluate a different set of criteria than that of nurses. These are attention to their condition, availability, concern and caring, skill, and respect. 
The fifth section addresses other hospital staff. Those chosen for evaluation were personnel commonly encountered in an acute care hospitalization. Staff mentioned in this section are housekeeping, laboratory, and X-ray.

The sixth section requests patient judgments of the living arrangements. This focuses more on the physical setting than on actual service personnel. This section covers condition of room, restful atmosphere, privacy, quality of food, hospital environment, and provisions for family and friends.

The seventh section addresses discharge from the hospital and contains eight questions. These questions relate to discharge procedures, discharge instructions, preparation for caring for self, coordination of care after discharge, explanations about costs and how to handle hospital bills, and efficiency of billing. Two additional questions address expectations of improvement in condition prior to hospitalization, and realization of expectations for improvement. The last two questions ask about positive unanticipated occurrences and negative unanticipated occurrences. These last two questions had room for comments. The last seven demographic questions ask for dates of hospitalization, reason for hospitalizacion, surgery received, area of hospital in which care was received, sex, age, and ethnicity providing eight choices.

The instrument adapted by Haw (1991) has not been tested for validity and reliability. Variations of the survey are in use at the target hospital through the current case management program. Data gathered through this study will be sent to Haw to assist in further development of the instrument.

\section{Analysis Procedures}

The information gathered by the researcher of the case managed group was compared to the information gathered several months before from the non-case managed group using the same questionnaire tool. Statistical comparisons were made using a nullhypothesis that the satisfaction reported by case managed patients is no different than the 
satisfaction reported by non-case managed patients. Responses of the first 43 questions were compared using mean satisfaction scores. Data were compressed for a crosstabulation of the ordinal data obtaining a $\chi^{2}$ and phi. The seven groups of questions were compared by group using the Mann-Whitney U. The Mann-Whitney U was selected because the research question asked if there was a difference in patients' perceptions of care and the data obtained were ordinal responses. The responses received were unequal in number which also made the Mann-Whitney $U$ the appropriate statistic to analyze them. The questionnaires remain the property of the hospital according to the protocol and will be part of ongoing data gathering related to nursing case management.

Permission to reprint Zander's conceptual framework was requested by mail and received for inclusion in this thesis (see Appendix G). The CMP used for the diagnoses of total hip replacements and total knee replacements was designed through the collaboration of the physicians, PNCM, department head, therapists, pharmacists, and nursing staff of the study unit.

\section{Summary}

This study used a quasi-experimental design with separate groups consisting of a case managed and a non-case managed population. All the patients had total joint replacements of the knee or hip and were cared for on the same unit of a district hospital in California. Patients were mailed a questionnaire in an effort to determine if there was a difference in the quality of the care they received as determined by the patients' perceptions. The respondents included 23 from the non-case managed group and 42 from the case managed group. The case managed group attended a pre-admission class offered by the PNCM. During this class the PNCM explained the plan of care, described the various activities in which they would be participating, and introduced them to the therapists who would be involved in their care. 
The questionnaire used was part of a hospital-wide evaluation of care. It contained 43 questions that were answered on a 5-point, excellent to poor scale in addition to demographic questions and comment areas. The answers to the 43 questions were analyzed using crosstabulations and the Mann-Whitney U. The questionnaire was mailed to each of the patients within 8 weeks following discharge from the hospital. Remailings were done as needed. The non-case managed patients were mailed the questionnaires directly by the study unit without a consent form per hospital policy. For the purpose of this study, the case managed patients were asked to sign a consent form to comply with IRB stipulations. 


\section{Chapter 4}

\section{FINDINGS AND INTERPRETATION}

The research question of this study was: Is there a difference in the way patients perceive that their needs are met in a case managed acute hospitalization compared to a non-case managed acute hospitalization? To answer this question, 65 subjects' responses to a patient satisfaction survey were statistically analyzed. Each had been hospitalized in the same unit of an acute care hospital with the same diagnosis and subsequent surgery for total joint replacement.

The non-case managed group contained 23 subjects. They participated in standard hospitalization procedures from admission to discharge. Following discharge they were mailed a questionnaire to obtain their perceptions of their hospitalization experience. The case managed group contained 42 subjects. The case managed group participated in a nursing case managed hospitalization. They were contacted prior to admission and included in classes held by the PNCM. Through the class the PNCM introduced the patients to the hospital patient rooms, physical therapists, equipment they would be using, and the staff on the hospital unit to which they would be admitted. They were given opportunities to ask individual questions and encouraged to contact the PNCM as needed. In addition, the hospital stay of the case managed group was planned in advance through the use of a critical pathway. The progress of each patient in the case managed group was closely monitored by the PNCM.

The non-case managed group consisted of 7 men, 15 women, and 1 declined to state. The mean age for the non-case managed group was 66 years. The mean number of hospitalized days for the non-case managed group was 7.6. The case managed group consisted of 12 men and 30 women. The mean age of the case managed group was 70.7 years. The mean number of days hospitalized for the case managed group was 7.8 days. 
The subjects classified their ethnic data as 61 Caucasian, 2 Chinese, and 2 declined to state.

\section{Analysis of Data}

A total of 43 questions pertaining to patient judgments of quality of care were graded on a Likert-type scale of 1-5 corresponding to excellent to poor. The responses to these questions were analyzed individually and in groups related to the presentation headings of admission, care in the hospital, nursing care, care by physicians, care by other hospital staff, living arrangements, and discharge procedures. The case managed patients reported better satisfaction with their care in the 43 questions to which they responded compared to the non-case managed group. This greater level of satisfaction did not reach statistical significance in the analyses performed. The answer to the research question was that there was no statistical difference in the way patients perceived that their needs were met in a case managed acute hospitalization compared to a non-case managed acute hospitalization. The data analysis did not yield probability levels which were sufficient to reject the null hypothesis $(\mathrm{p}<.05)$.

In order to simplify data analysis, the questions 1 through 43 were grouped in the categories in which they were presented to the subjects in the questionnaire. A mean ranking was calculated with the lower ranking constituting a higher level of satisfaction. Statistical analysis was performed using a Mann-Whitney U. The statistic for testing the hypothesis that the two distributions are equal is the sum of the ranks for each of the groups. The mean rank is the sum of the ranks divided by the number of cases. The results were as follows: The first category contained questions 1 to 4 and was directed toward the admission procedures of entering the hospital. The case managed group contained 41 responses with a mean rank of 32.0. The non-case managed group contained 21 responses with a mean rank of 31.0 .

The second category contained 19 questions and related to overall care in the 
hospital. This section contained questions regarding overall consideration given to the patient, information and instructions given, perceptions of therapists, coordination of care, and involvement of family and friends. The respondents contained 12 from the noncase managed group with a mean rank of 22.3 and 26 from the case managed group with a mean rank of 18.2 .

The third category contained five questions. These questions asked directly about nursing care. The case managed group contained 37 respondents and yielded a mean rank of 29.0. The non-case managed group contained 18 respondents with a mean rank of 25.9 .

The fourth group contained five questions. These related to overall satisfaction with care by physicians. The case managed group yielded 33 responses with a mean rank of 25.5. The non-case managed group yielded 17 responses with a mean rank of 25.4 .

The fifth category contained three questions regarding hospital staff. These included perceptions regarding the laboratory, housekeeping, and x-ray staff. Twentyeight subjects in the case managed group responded with a mean rank of 21.3. Twelve in the non-case managed group responded with a mean rank of 18.6.

The sixth category contained 6 questions about the living arrangements in the hospital. These included questions on the environment, food, privacy, and similar items. The case managed group yielded 32 respondents with a mean rank of 25.7. The non-case managed group consisted of 19 respondents with a mean rank of 26.5 .

The last category contained six questions. These questions asked about planning for discharge and included questions regarding coordination of care and billing procedures. The results contained 11 responses from the non-case managed group with a mean rank of 19.3 and 31 responses from the case managed group with a mean rank of 22.3 .

None of the results in these groups reached statistical significance. The mean 
scores of the groups showed little difference in five categories and a higher level of satisfaction with the case managed group in two categories. These were the categories of overall care and care by physicians. The mean score for overall care in the case managed group was 1.59 compared with 1.83 for the non-case managed group. The mean score for satisfaction with physicians among case managed patients was 1.39 compared with 1.58 for non-case managed patients.

None of the first 43 questions comparing the case managed group and non-case managed group yielded results of statistical significance. The respondents in both groups scored most questions in the excellent, very good and good categories. To balance the data for a different analysis, the responses were compressed into 2 categories. The first category contained those who scored their perceptions of care as excellent. The second category was a composite of all answers in the very good to poor categories. By compressing the data in this manner, reliable $\mathrm{p}$ values could be obtained without violating assumptions (cells with expected frequencies of 5 or less $<25 \%$ ). Crosstabulations with a $\chi^{2}$ and phi were obtained with this regrouping comparing the case managed group to the non-case managed group. None of the questions obtained results that were statistically significant through this regrouping. 


\section{Chapter 5}

\section{DISCUSSION}

This study sought to determine whether changing a care delivery system adversely affected patients' perceptions of their quality of care. As discussed earlier, the driving force of nursing case management is cost containment. The researcher is aware that a potential danger in any effort to contain costs is a decrease in quality. This study provides some answers to address that concern.

It is of interest that the areas of care rated highest in satisfaction by the case managed group compared to the non-case managed group were the areas of overall care and care by physician. Although not of statistical significance, the patients in the case managed group were more satisfied with their physicians as reported in each of the physician related questions. This could be related to the orientation given by the PNCM which prepared the patients to appreciate and understand the communication received from their physicians. Also, the instruction given by the PNCM related to hospital routine could have influenced the case managed group's more positive reaction to overall care. Conversely, in each question related to discharge procedures, the case managed group rated care less satisfactory than the non-case managed group. Preparation for discharge is a focus area of the PNCM; however, patients' less satisfactory perceptions could be indicative of patients feeling rushed. This also could be a reflection of the 5 year difference in mean age between the case managed group and the non-case managed group. The older case managed group could have required more time to adjust to the change of discharge.

The study determined that there was no significant difference in the quality of care received by case managed patients compared to non-case managed patients. In the conceptual model used for this study, Zander refers to the patient as the product 
(Zander, 1988). The end product of this care delivery system (the patient) reported high quality results which were achieved within standard costs and time frames.

In light of TQM objectives, this study provides useful data to direct patient care improvement in several areas. The study provides valuable information related to the primary question of patient satisfaction. This is a necessary component of the feedback section of the conceptual model on which this care delivery system is based. Without ongoing reliable data from the patients themselves, an accurate evaluation of their view of the care they received cannot be obtained. The results of this study aid in filling that void.

\section{Scope and Limitations}

The research was limited by the availability of patients with the target diagnoses admitted to the target unit at the time of study. The study was carried out on one unit of the hospital to maintain internal consistency. The results may not be representative of other units within the hospital or how other patient populations with other diagnoses would have responded.

The population included those with chronic disease who may have been debilitated severely enough to interfere with participating in the study by returning the questionnaire. In the returned questionnaires, many questions were left blank. This may have been because the print size was small and difficult to read. The majority of the respondents were elderly and, as stated earlier, the senses decrease in acuity in old age. Several patients did not turn the questionnaires over to answer the questions on the back but instead treated it as if it were only printed on one side. The tool itself may not have been well adapted to a geriatric population; moreover, it should be noted that the tool was somewhat lengthy, which could have had an adverse effect on response rates.

The diagnosis chosen for this study is one which primarily affects geriatric patients. Upon analyzing the data, the researcher found that the non-case managed group 
contained 4 patients under 60 . The case managed group contained 7 patients under 60 . The mean age for each group was well within geriatric range. For the purpose of this study, it was decided not to control for age and to leave these subjects in the data. Future studies examining an exclusively geriatric population should control for age.

The implementation of nursing case management by nursing administration necessitated that all patients with the target diagnosis be case managed at one time. This did not allow for the creation of a random design which would have provided a sironger study. The researcher was limited by the number of patients who constituted the noncase managed group. Those patients had already been sent a questionnaire and the returned questionnaires were existing data and hospital property. Case management had already been implemented on the target unit so the possibility of obtaining a larger noncase managed group was not an option.

It should be noted that the case managed group had a mean age 5 years older than the non-case managed group. This could have had an effect on LOS, increased complications, and time required by the patients to assimilate the PNCM teaching prior to admission and at discharge. As mentioned earlier geriatric patients tend to have more chronic health problems which increase with age (Schefft \& Lehr, 1990).

Case management was implemented throughout one unit of the hospital for the specific diagnoses of total hip and total knee replacements. The surveys were mailed to the first group of non-case managed patients without obiaining a prior consent form under the direction of nursing administration, in accordance with hospital policy. For the purpose of this study, the case managed patients were asked to sign a consent form prior to their leaving the hospital granting permission for the questionnaire to be mailed to them. Having to place their signature on the consent form may have biased their responses and removed the perceived protection of anonymity that the previous group experienced. 
A major earthquake had occurred prior to the initiation of the study. The case managed group was subject to hospital repairs that were occurring on the unit and throughout the hospital during the time they were hospitalized. This could have had an adverse effect on their responses to the questions regarding living conditions. The repair work was disruptive to the staff as well and could have had an adverse effect on the staff. Normally used stairways and hallways were periodically blocked off. False walls were constructed to allow construction workers to be separate from the patients and staff activities. This construction could have changed the normal manner in which the staff would have responded to patient needs.

\section{Recommendations}

The researcher sees the need to repeat this study with a larger control group and study group. Plans for more nursing case management are under way by hospital administration. It is important that a full evaluation of the patient's perceptions of care be obtained prior to making a change in the care delivery system. This should be done throughout each unit of the hospital with an adequate number of patients to yield useful data. After implementation of nursing case management, another data set should then be gathered so comparisons can be made.

An experimental design using randomly chosen subjects would be preferred. The researcher is aware, however, that once case management is implemented on a nursing unit, the care for all patients is affected whether they are case managed or not. It is difficult to train a staff and then ask them to treat one group of patients differently than another. Unless almost identical units exist within a setting where similar diagnoses are admitted, conducting a randomly controlled study would be difficult.

Specific questions relating to the behavioral objectives of the PNCM also should be included in further studies. Questionnaires might be tailored to each specific unit and the speciality of that department. Data then could be incorporated into unit based staff 
development and guide further understanding of patient perspectives of care. Data could also be used to encourage and provide positive reinforcement for patient reported areas of excellence in care delivery.

The number of acute care hospital beds is declining as more care is being transferred to the community. This tool could be tailored to the community nursing case managed patients and aid in those TQM programs. Each area of nursing case management is in need of evaluation from the patient perspective. Additional evaluations from the perspectives of the health care team using a similar questionnaire tool would also provide valuable information to guide the development of nursing case management.

\section{Conclusions}

The results of this study indicated there is no difference in patients' perceptions of their care through a case managed hospitalization compared to a non-case managed hospitalization. Nursirg case management is being implemented in many areas of this country in an attempt to decrease LOS and insure quality of care. This study indicated that quality of care is perceived to be as high by case managed patients as non-case managed patients. This corresponds to information in the literature review but provides quantitative information for support.

In an effort to provide cost containment, managed care is on the horizon for most providers of acute hospital care. The nursing profession needs to take proactive steps towards the development and evaluation of new modes of health care delivery. Nurses have always acted as patient advocates, teachers, and caregivers. It is imperative that the nursing profession be in the forefront of change. Development of new care-delivery systems should be: patient focused, grounded in sound nursing theory, evaluated through research, and able to meet the requirements of TQM including cost containment parameters. This is a challenge the nursing profession is well equipped to meet. 


\section{REFERENCES}


References

Cohen, E. L., (1991). Nursing case management: Does it pay? Journal of Nursing Administration, 21(4), 2-25.

Cronin, C. J., \& Maklebust, J. (1989). Case-managed care: Capitalizing on the CNS. Nursing Management, 20 (3), 38-47.

Dunston, J. (1990). How managed care can work for you. Nursing 90, 20(10), 56-59.

Ethridge, P. (1991). A nursing HMO: Carondelet St. Mary's Experience. Nursing Management, 22(7), 22-27.

Ethridge, P., \& Lamb, G. S. (1989). Professional nursing case management improves quality, access and costs. Nursing Management, 20(3), 30-47.

Geigle, R., \& Jones, S. B. (1990). Outcomes measurement: A report from the front. Inquiry, 27, 7-13.

Haw, M. A., (1991). Patient's judgements of hospital quality on 5 east. Unpublished manuscript.

Henderson, M. G., \& Collard, A. (1988). Measuring quality in medical case management programs. Quality Review Bulletin, 14(2), 33-39.

Henderson, M. G., Souder, B. A., \& Bergman, A. (1987, October). Measuring efficiencies of managed care. Business and Health, pp. 43-46.

Holt, F. M. (1990). The clinical nurse specialist - Luxury or necessity? Clinical Nurse Specialist, $\underline{4}(3), 141$.

Longino, C. F., Soldo, B. J., \& Manton, K. G. (1990). Demography of aging in the United States. In K. F. Ferraro (Ed.), Gerontology Perspectives and Issues (pp. 1941). New York: Springer Publishing Company.

Lulavage, A. (1991). RN-LPN teams: Toward unit nursing case management. Nursing Management, 22(3), 58-61. 
Meterko, M., \& Rubin, H. R. (1990). 2. Patient judgements of hospital quality: A taxonomy. Medical Care Review, 28(9) (Suppl.), S10-S14.

Norris, M. K. G., \& Hill, C. (1991). The clinical nurse specialist: Developing the case manager role. Dimensions of Critical Care Nursing, 10(6), 346-353.

Pittman, K. P. (1991). Care: A case management model for empowering hospital nurses. The Florida Nurse, $\underline{39}(10), 4-6$.

Rubin, H. R. (1990). Can patients evaluate the quality of hospital care? Medical Care Review, 47(3), 267-326.

Scheff, B. K., \& Lehr, B. K. (1990). Psychological problems of older adults. In K. F. Ferraro (Ed.), Gerontology Perspectives and Issues (pp. 287-287). New York: Springer.

Spross, J. A. (1989). The CNS as collaborator. In Hamric, A. B., \& Spross, J. A. (Ed.), The Clinical Nurse Specialist in Theory and Practice (pp. 205-226). Philadelphia: W. B. Sanders.

Vuori, H. (1987). Patient satisfaction: An attribute or indicator of the quality of care? Quality Review Bulletin, 13(3), 105-108.

Wahlstedt, P., \& Blaser, W. (1986). Nurse case management for the frail elderly: A curriculum to prepare nurses for that role. Home Healthcare Nurse, $\underline{4}(2), 30-35$.

Wimberley, E. T., \& Blazyk, S. (1989, November). Monitoring patient outcome following discharge: A computerized geriatric case-management system. Health and Social Work, pp. 269-276.

Williams, B. S. (1991). The utility of nursing theory in nursing case management practice. Nursing Administration Quarterly, 15(3), 60-65.

Winslow, R. (1992, July 7). Questionnaire probes patient's quality of life. The Wall Street Journal, pp. B1, B5. 
Zander, K. (1988). Managed care within acute care settings: Design and implementation via nursing case management. Health Care Supervisor, $\underline{6}(2), 27-43$. 
APPENDIX A

Institutional Review Board Approval Letter 


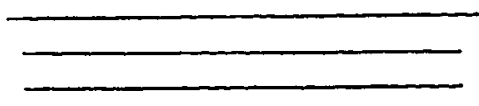

January 17, 1992

Nancy J. Woodward, R.N.

3400 Warburton Ave.

Santa Clara, CA 95051-2707

RE: The Effect of Nursing Care Management on Geriatric Clients Following Acute Hospitalization

Dear Ms. Woodward:

The Institutional Review Board reviewed your protocol at its meetings on December 20 , 1991 , and January 17, 1992. The members of the committee recommended approval of your study at with several qualifications.

1. Patients will need to receive a consent form assuring them of anonymity and protection of the integrity of their medical record prior to mailing the questionnaire.

2. The patients to be studied, i.e. the diagnosis to be studied, will need to be included in an addendum to your protocol.

3. The members of the Institutional Review Board felt that your study would gain more significance if a randomized design had been employed. Since this appears to not be possible, the members have strongly suggested that you adequately discuss the limitations of your study using historical controls.

This appears to be a significant shortcoming in your study protocol and will need to be discussed in your thesis.

If you have any further questions, please do not hesitate to contact us.

Sincerely,

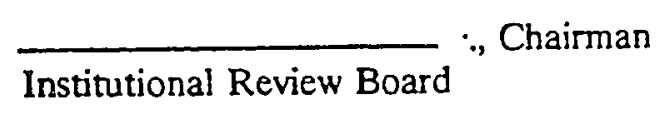




\section{APPENDIX B}

Human Subjects-Institutional Review Board Approval Letter 
Olfice of the Academic Vice President - Associate Academic Vice President - Graduate Studies and Research

One Washington Square • San Jose. California 95192-0025 • 408/924-2480

To: Nancy J. Woodward, Nursing

3400 Warburton Avenue

Santa Clara, CA 95051-2707

From: Serena w. stanford ferena H. Hexpore
AAVP, Graduate studies and Research

Date: March 12, 1992

The Human Subjects-Institutional Review Board has approved your request to use human subjects in the study entitled:

"The Effect of Nursing Case Management on Geriatric Patients Following Acute Hospitalization"

This approval is contingent upon the subjects participating in your research project being appropriately protected from risk. This includes the protection of the anonymity of the subjects' identity when they participate in your research project, and with regard to any and all data that may be collected from the subjects. The Board's approval includes continued monitoring of your research by the Board to assure that the subjects are being adequately and properly protected from such risks. If at any time a subject becomes injured or complains of injury, you must notify $\mathrm{Dr}$. Serena stanford immediately. Injury includes but is not limited to bodily harm, psychological trauma and release of potentially damaging personal information.

Please also be advised that each subject needs to be fully informed and aware that their participation in your research project is voluntary, and that he or she may withdraw from the project at any time. Further, a subject's participation, refusal to participate or withdrawal will not affect any services the subject is receiving or will receive at the institution in which the research is being conducted.

If you have questions, please contact me at 408-924-2480.

CC: Terry W. Miller, Nursing 
APPENDIX C

Questionnaire 


\section{PATIENT JUDGEMENTS OF HOSPITAL QUALTTY ON.}

Please answer all of the questions to follow. If you wish to comment on any questions or qualify your answers, please feel free to use the spaces in the margins. Your comments will be read and appreciated! First, we would like you to rate some things about your care at

- in terms of whether they were excellent, very good, good, fair or poor. Please carcle only one rating for each statement.

\section{ADMISSION: ENTERING THE HOSPITAL}

1. PREPARATION FOR ADMISSION: How clear and complete the information was about how to prepare for your stay in the hospital and what to expect once you got there

2. EFFICIENCY OF THE ADMITTING PROCEDURE: Ease of getting admitted, including the amount of time it took

3. HELPFULNESS AND CONCERN OF ADMITTING STAFF: Their courtesy and concem for your comfort and feelings

4. ATTENTION OF ADMITTING STAFF TO YOUR INDIVIDUAL NEEDS: Their flexibility in handling your personal needs and wants

\section{YOUR CARE IN THE HOSPITAL}

5. MEDICAL FACILITIES: How complete and up-to-date the medical equipment was

6. OVERALL EFFICIENCY OF HOSPITAL: How smoothly things ran

7. RECOGNITION OF YOUR OPINION: Asking you what you think is important and giving you choices

8. CONSIDERATION OF YOUR NEEDS: Willingness to be flexible in meeting your needs

9. INFORMATION YOU WERE GIVEN: How clear and complete were the explanations about tests, treatments and what to expect

10. INSTRUCTIONS: How well doctors, nurses and other staff explained how to prepare for tests and operations
Very Don't

Excellent Good Good Fair Poor Know

Excellent Good Good Fair Poor Know

Very Don't

Very Don't

Excellent Good Good Fair Poor Know

\begin{tabular}{|c|c|c|c|c|c|}
\hline Excellent & $\begin{array}{l}\text { Very } \\
\text { Good }\end{array}$ & Good & Fair & Poor & $\begin{array}{l}\text { Don't } \\
\text { Know }\end{array}$ \\
\hline Excellent & $\begin{array}{l}\text { Very } \\
\text { Good }\end{array}$ & Good & Fair & Poor & $\begin{array}{l}\text { Don't } \\
\text { Know }\end{array}$ \\
\hline Excellent & $\begin{array}{l}\text { Very } \\
\text { Good }\end{array}$ & Good & Fair & Poor & $\begin{array}{l}\text { Don't } \\
\text { Know }\end{array}$ \\
\hline Excellent & $\begin{array}{l}\text { Very } \\
\text { Good }\end{array}$ & Good & Fair & Poor & $\begin{array}{l}\text { Don't } \\
\text { Know }\end{array}$ \\
\hline Excellent & $\begin{array}{l}\text { Very } \\
\text { Good }\end{array}$ & Good & Fair & Poor & $\begin{array}{l}\text { Don't } \\
\text { Know }\end{array}$ \\
\hline Exce & $\begin{array}{l}\text { Very } \\
\text { Good }\end{array}$ & Good & Fair & Poor & $\begin{array}{l}\text { Don't } \\
\text { Know }\end{array}$ \\
\hline
\end{tabular}

(over) 
YOUR CARE IN THE HOSPITAL continued:

11. COORDINATION OF CARE: The teamwork of all the hospital staff who rook care of you

12. THE DAILY ROUTINE OF THE DOCTORS, NURSES AND HOSPITAL STAFF: How well they adjusted their schedules to your needs

13. INFORMING FAMILY OR FRIENDS: How well they were kept informed about your condirion and needs

14. INVOLVING FAMILY OR FRIENDS IN YOUR CARE: How much they were allowed to help in your care

15. EASE OF GETTING INFORMATION: Willingness of hospital staff to answer your questions

16. SPECLAIISTS AND SPECLAL THERAPY: Availability of getting the specialized tests, medicines or treatments you needed

17. HELPFULNESS: Ability of hospital staff to make you comfortable and reassure you

18. SAFETY AND SECURITY: The provisions for your safety and the security of your belongings

YOUR NURSES:

19. SKIIL AND COMPETENCE OF THE NURSES: How well things were done, like giving medicine and handling IVs

20. ATTENTION TO YOUR CONDITION: How often nurses checked on you and how well they kept track of how you were doing

21. NURSING STAFF RESPONSES TO YOUR CALLS: How quick they were to lieip

22. CONCERN AND CARING BY NURSES: Courtesy and respect you were given; friendliness and kindness
Very Don't

Excellent Good Good Fair Poor Know

Very

Very Don't

Very Don't

Very Don't

Very Don't'

Excellent Good Good Fair Poor Know

$\begin{array}{cccc}\text { Very } & & \text { Don't } \\ \text { Excellent Good Good Fair Poor } & \text { Know } \\ & \text { Very } & & \\ \text { Don't } \\ \text { Excellent Good Good Fair Poor Know }\end{array}$

Very 4 Don't

Excellent Good Good Fair Poor Kon't

Very Don't

Excellent Good Good Fair Poor Know

Very Don't

Excellent Good Good Fair Poor Know: 
YOUR NURSES continued:

23. INFORMATION GIVEN BY NURSES: How well nurses communicated with patients, families and doctors

\section{YOUR DOCTOR}

24. ATTENTION TO YOUR CONDITION: How of ten the doctors checked on you and how well they kept track of how you were doing

25. AVAILABILITY OF DOCTOR: How easy it was to get your doctor when needed

26. CONCERN AND CARING BY DOCTOR: courtesy and respect you were given, friendliness and kindness

27. SKILL OF DOCTOR: Ability to diagnose problems, thoroughness of examinations, skill in treating your condition, and scientific knowledge

28. RESPECT FOR YOU: How well the doctor listened to what you had to say, how well the doctor understood what you thought was important

\section{OTHER HOSPITAL STAFF}

29. HOUSEKEEPING STAFF: How well they did their job and how well they acted towards you

30. LABORATORY WORKERS: How well they did their jobs and how they acted towards you

31. X-RAY STAFF: How well they did their jobs and how they acted towards you

\section{LIVING ARRANGEMENTS}

32. CONDITION OF YOUR ROOM: cleanliness, comfor, lighting and temperarure

33. RESTFUL ATMOSPHERE: Amount of feace and quiet

34. PRIVACY: Provisions for your privacy

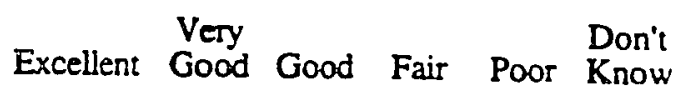

Excellent Very Don't

Very Don't

Excellent Good Good Fair Poor Know

Very Don't

Excellent Good Good Fair Poor Know

Excellent Very Dor't

Eood Good Fair Poor Know

Excellent Good Good Fair Poor $\begin{gathered}\text { Don't } \\ \text { Know }\end{gathered}$

Excellent Very Don't

Excellent Good Good Fair Poor Know

Very Don't

Excellent Good Good Fair Poor Know

Excellent Good Good Fair Poor Know

Excellent Good Good Fair Poor Know

Very Don't

Very Don't

Excellent Good Good Fair Poor Know (over) 
LIVING ARRANGEMENTS continued:

35. QUALITY OF FOOD: Overall, how well it tasted, serving temperature, and variety available

36. HOSPITAL ENVIRONMENT: Other than your room, how comfortable, quiet and pleasant it was

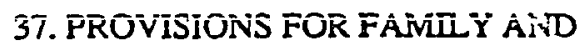
FRIENDS: Adequacy of visiting hours and facilities for them, visitors treated like welcome guests

\section{DISCHARGE: LEAVING THE HOSPITAL}

38. DISCHARGE PROCEDIJRES: Time it took to be discharged from the hospital and how efficiently it was handled

39. DISCHARGE INSTRUCTIONS: How clearly and completely you were told what to do and what to expect when you left the hospital

40. PREPARATION FOR CARING FOR YOURSELF: How well you (or your caregiver) were prepared for managing your care at home

41. COORDINATION OF CARE AFTER DISCHARGE: Hospital staff's effors to provide for your needs after you left the hospital

42. EXPLANATIONS ABOUT COSTS AND HOW TO HANDLE YOUR HOSPITAL BILLS: The completeness and accuracy of information and the willingness of hospital staff to answer your questions about finances

43. EFFICIENCY OF BILLING: How fast you got your bill, how accurate and understandable it was

14. Think back to the time just before you entered the hospital. Did you think your health orcondition would be helped or improved by your stay in the hospital...

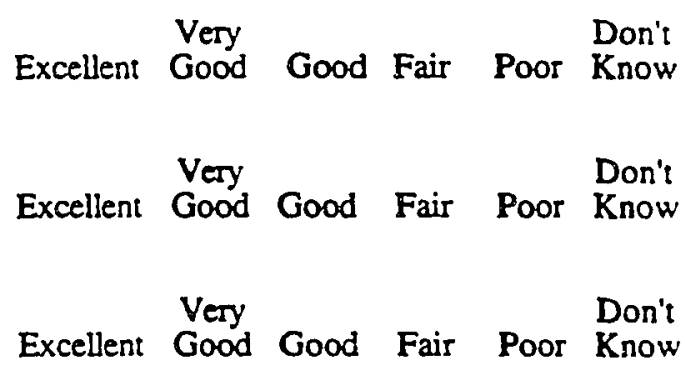

Very
Excellent Good Good Fair Poor Know

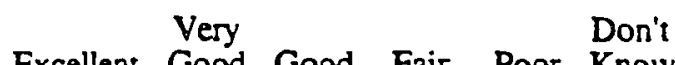

Very Don't

Excellent Good Good Fair Poor Know

Very Don't

Excellent Good Good Fair Poor Know

Excellent Good Good Fair Poor $\begin{array}{r}\text { Don't } \\ \text { Know }\end{array}$

Excellent Good Good Fair Poor Know

$\begin{array}{ccccc}\text { A great } & \begin{array}{c}\text { Quite } \\ \text { deal }\end{array} \text { a bit } & \begin{array}{c}\text { Some- } \\ \text { what }\end{array} \text { litle } & \begin{array}{c}\text { Not } \\ \text { at all }\end{array} & \begin{array}{c}\text { Not sure; } \\ \text { does not } \\ \text { apply }\end{array}\end{array}$ 
45. Now that you have been out of the hospital for a while, how much do you think you were actually helped by your hospital stay? Do you think

A great Quite Some- A Not Not sure; deal a bit what little at all does not apply you were helped...

46. Did anything good happen during your stay in the hospital that surprised you?

yes (please describe):

47. Did anything bad happen during your stay in the hospital that surprised you?

no

yes (please describe):

\section{FACTS ABOUT YOU}

These nexi few questions are for statistical purposes. These answers will be kept strictly confidential.

48. What were the dates that you were in Hospital? (Your most recent stay only)

Entered the Hospital $\frac{1}{\text { month day year }}$

Left the Hospital

$\frac{1}{\text { month day year }}$

49. What was the main reason or type of problem that led to this hospitalization? (one answer please)

bone, joint or tendon problem
brain or spinal problem
broken bone, fracture or accidental injury
cancer or cancer-related problem
diabetes
cye, ear, nose or throat problem
hear problem
intestinal, stomach or digestive problem
kidney or urinayy problem

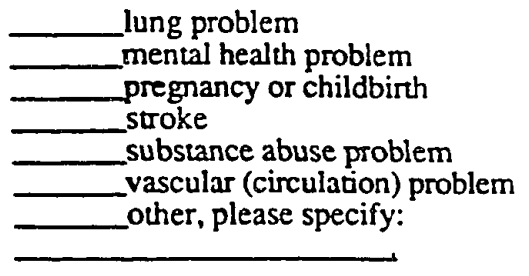

50. Did you have surgery during this hospitalization?

yes; if yes, describe what kind: no 
51. During this hospitalization, in which area did you spend most of your stay? (one answer please)

\begin{tabular}{l}
6 East \\
\hline 5 East \\
\hline Transitional Care Unit \\
2 East \\
\hline Matemity \\
1 South
\end{tabular}

$\begin{array}{r}6 \text { West } \\ 55 \text { West } \\ 4 \text { West } \\ 3 \text { West } \\ 22 \text { West } \\ \hline \text { Critical Care } \\ \hline \text { Other, please specify: } \\ \hline\end{array}$

52. What is your sex?

female

53. What is your age?

54. What ethnic group do you consider yourself?

\begin{tabular}{l} 
Caucasian (White) \\
African American (Black) \\
Hispanic \\
Native American, Eskimo \\
Chinese \\
\hline Japanese \\
Other Asian \\
Other, please specify:
\end{tabular}

If you have any questions or concems regarding _—_ you may call the Patient Support Services Staff at Thank you for completing the survey. Please retum this survey in the envelope provided (postage is pre-paid). 
APPENDIX D

Cover Letter 
Dear Patient:

We hope you are recovering vell from your recent stay on - at

We are doing a special study of patient care on and would greatiy value your ideas.

The enclosed survey asks for your opinions about the care you received at help us greatly in evaluating the quality of patient care on

Your responses will be kept strictly confidential. The staff will receive a summary of results from a large number of wour individual responses will be kept in strict confidence. Hospital personnel will review the individual returned questionnaires and your comments taken into consideration.

A self-addressed, postage-paid envelope is enclosed for your convenience. Please return your survey within two weeks so that we may evaluate patient care in a timely manner.

If you have any questions about this survey, please phone me at. Thank you for your assistance.

sincerely,

Department Head, 
APPENDIX E

Patient Consent Form 


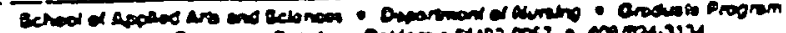

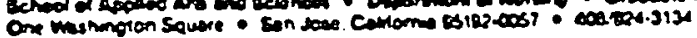

AGREEMENT TO PARTICIPATE IN RESEARCH

SAN JOSE STATE UNIVERSITY

Responsible Investizator: Nancy J. Foodward RNC

Type of Protocol: Patient JudBements of Hospital Quality mailed survey

1 have been asked to participate in a research study that is investigating patient satisfaction of care given them in the hospital. The results of this study should further our understanding of what patient's deem important to them while in the hospital.

I understand that:

1) I will be asked to fill out and return by mall an anonymous questionnaire of under 60 questions that will be mailed to my home after discharge from the hospital. I understand that 1 am free to omit any questions I choose not to answer.

2) No anticipated risks are expected as a result of participating in this study.

3) The possible benefits of this study to me are that the hospital will gain from a knowledge of my viewpoint which may benefit me in any further hospitalizations.

4) No treatments will be withheld as a result of participating or not participating in this study.

5) The results of this study may be published, but any information from this study that can be identified with me will remain strictly confidential.

6) There will be no compensation as a result of participation in this study.

7) Any questions about my participation in this study will be answered by Nancy Toodward RNC 408-296-3723 or 415-940-7103. Complaints about the procedures may be presented to Tersy Miller RN PhD 408-924-3130. For questions or complaints about research subject's rights, or in the event of research-related injury, contact Serena Stanford PhD (Associate Academic Vice President for Craduate Studies \& Research) at 9242480and/or the IRB committee, Medic J Stairi Orifice,

8) No service of any kind that I may otherwise be entitled to will be lost or jeopardized if I choose not to participate in this study.

9) My consent is given voluntary; I may refuse to participate in this study or in any part of this study, and I may $\forall$ ithdray at any time without prejudice to my relations with

SJSU or

10) I have received a copy of this consent form for my file.

I HAVE MADE A DECISION WHETHER OR NOT TO PARTICIPATE. MY SICNATURE INDICATES THAT I HAVE READ THE INFORMATION PROVIDED ABOVE AND THAT I HAVE DECIDED TO PARTICIPATE.

THE SICNATURE OF THE RESEARCHER ON THIS DOCUMENT INDICATES ACREMENT TO INCLUDE THE ABOVE NAMED SUBJECT IN THE RESEARCH AND ATTESTS THAT THE SUBJECT HAS BEEIV FULLY INFURWED OF HIS OK HER KICATS.

DATE INVESTICATOR'S SICNATURE $\quad$ DATE SUBJECT'S SICNATURE




\section{APPENDIX F}

Consent letter to Use Questionnaire 


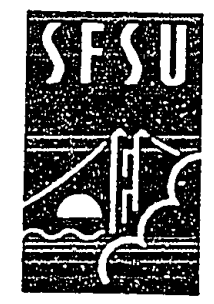

San Francisco State University

1600 Holloway Avenue

San Francisco, California 94132
Department of Nursing 415/338-1801

October 21, 1992

Nancy Woodward

3400 Warburton Avenue

Santa Clara, CA 94051-2707

Dear Nancy:

This letter is in response to your request to use the Patient's Judgments of Hospital Quality on survev instrument used in the program evaluation study of the new care delivery system at As you know, I adapted this survey instrument from the Patient's Judgment of Hospital Quality instrument published in Medical Care, 28 (9S), 1991 (please note that the authors of this instrument intended that this instrument "be regarded as in the public domain" (p. S44). I wish you the best in conducting your study and look forward to hearing about the results.

Sincerely,

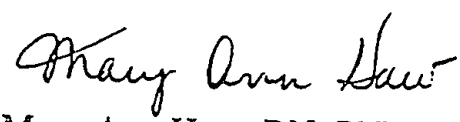

Mary Ann Haw, RN, PhD

Professor 
APPENDIX G

Consent Letter to Reprint Conceptual Framework Diagram 


\section{THE CENTER for CASE MANAGEMENT, INC.}

6 Pleasant Street - South Natick, MA 01760

Tel: 508-651-2600 - Fax: 508-655-0858

Nancy Woodward RNC

3400 Warburton Avenue

Santa Clara, CA 95051-2707

Dear Ms. Woodward,

This is in response to your request of October 15, 1992. I am pleased to grant you permission to reprint the Nursing Case Management Model diagram in your Masters thesis and subsequent publications. This was printed in "Managed care within acute care settings: Design and implementation via nursing case management" in Heatth Care Supervisor, 1988, 6(2) $27-43$.

Please let me know if we can be of any further assistance to you in your case management project.

Sincerely,

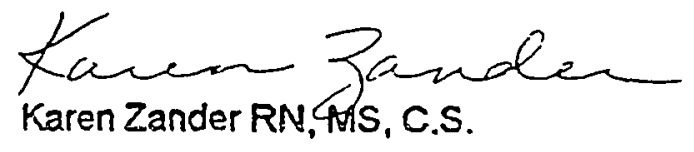

